\title{
PRESENCE OF CALCIFIED TISSUE IN THE HUMAN TEMPOROMANDIBULAR JOINT DISC
}

\author{
CARLA MARCHETTI, ${ }^{1, *}$ GIORGIO BERNASCONI ${ }^{2}$ and \\ MARCELLA REGUZZONI' \\ Istituto di Istologia ed Embriologia Generale and 'Istituto di Discipline Odontostomatologiche. \\ Universita(c) di Pavia, Via Forlanini 10.27100 Pavia, Italy
}

(Accepted 11 March 1997)

\begin{abstract}
Summary - Large calcified areas were observed in the articular discs of the temporomandibular joint from five patients suffering from articular dysfunctions. The calcified regions were always located inside the fibrous tissue of the discs. They had a woven bone-like morphological pattern and consisted of a compact mineralized tissue containing cells in irregular lacunae. In all the samples the calcified tissue was completely surrounded by a mineralizing border rich in cells and variously arranged collagen fibrils. Energy-dispersive spectrometry showed that mineralized regions contained large amounts of $\mathrm{Ca}$ and $\mathbf{P}$. $\mathrm{X}$-ray powder diffraction identified the crystals in these areas as hydroxyapatite. $\odot 1997$ Elsevier Science Ltd
\end{abstract}

Key words: temporomandibular joint, articular disc, calcification, TEM. EDS, XRD.

\section{INTRODUCTION}

Several studies have been performed on the microscopic and ultrastructural features of the fibrous component of the temporomandibular joint disc (Oberg and Carlsson, 1979; Bhussry et al., 1991; Berkovitz et al., 1992) and on its structural modifications following articular dysfunctions (Carlsson et al., 1967; Sharawy et al., 1987; Helmy et al., 1988, 1989; Piacentini et al., 1994; Marchetti et al., 1995). Less is known about the non-fibrous extracellularmatrix components and the possible metaplastic modifications of the tissue.

The chemical composition of the articular disc of the temporomandibular joint is modified during maturation and growth. In particular, increased amounts of chondroitin-6-sulphate and keratan sulphate/chondroitin-4-sulphate and the appearance of a cartilaginous phenotype are observed during mandibular growth. These variations were seen as a response of the articular disc to changes in the mechanical loading (Mills et al., 1988; Carvalho et al., 1993). Cartilaginous cells have also been found in discs from ageing humans (Oberg and Carlsson, 1979; Bhussry et al., 1991; Berkovitz et al., 1992). Moreover, small deposits of mineralized material in the fibrous tissue were observed among the age-related changes in the articular disc. They were describes as foci of variously shaped mineral precipitates localized in the intercellular matrix (Shaw and Molineux, 1994). Our aim now was to investi-

*To whom all correspondence should be addressed. gate the morphological and chemical characteristics of calcification occurring in disc tissue due to articular dysfunctions.

\section{MATERIALS AND METHODS}

The study was made on five discs from individuals aged 45-53 years belonging to a group of 71 patients who underwent arthroscopy and arthrotomy because of large functional defects of the mandibular joint. To select patients for arthroscopy and surgery our diagnostic and therapeutic protocols estimate the functional damage by reference to the degree of articular pain and the clinical history. The functional damage we observed in all our patients was consistent with the presence of more than one of the defects involved in the hypothesis of internal derangement and arthrosis of the mandibular joint (Farrar, 1972; Stegenga et al., 1989). The five patients who presented calcified disc lesions had very similar symptoms and clinical histories. They all remembered having articular noise and some dynamic limitation of the condyles from many years, and they all began to suffer from articular pain more than 5 years ago. They had all been given conservative treatment (physiotherapy and bite-planes) which had produced only some small and temporary relief. The articular pain began as a small and transitory problem and increased to become a very important and disabling pathology in a variable but sudden period before we first saw them. The presence of calcifications within the disc was diagnosed radiologically (orthopantomography, 

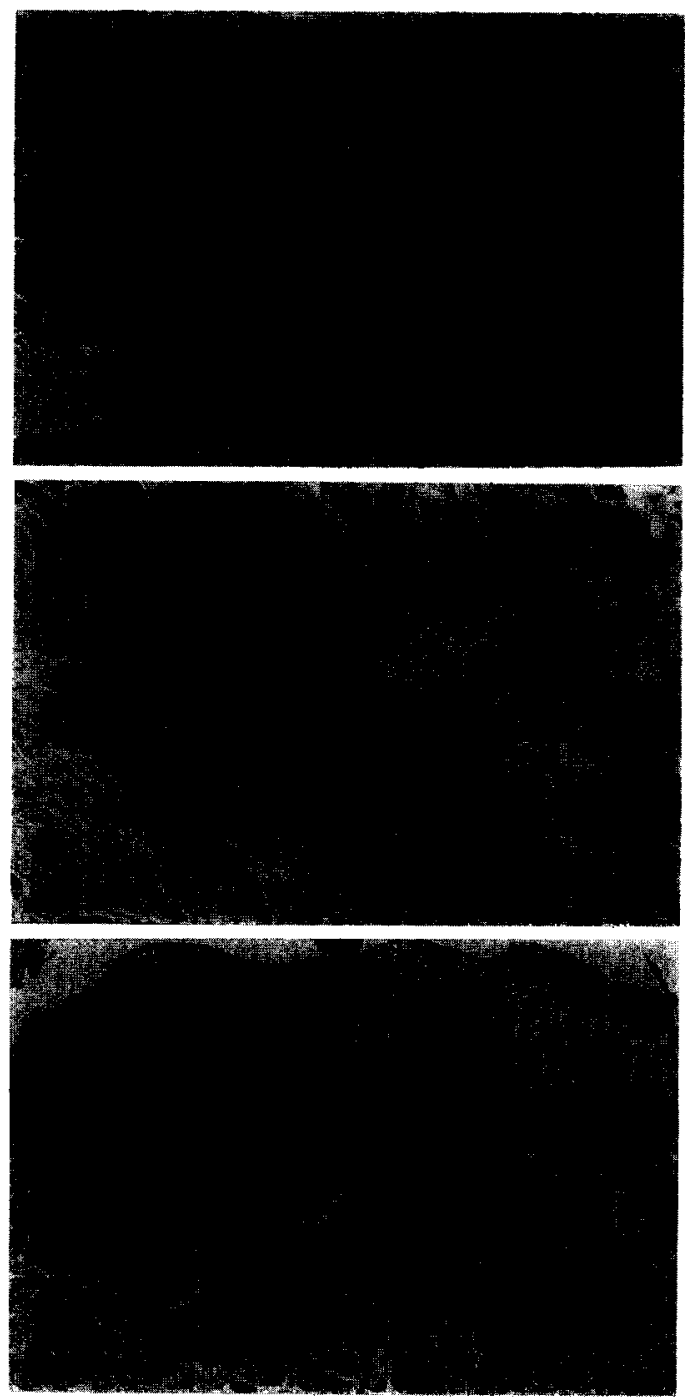

Fig. 1. Peripheral soft tissue of the disc composed of compact bundles of collagen fibres with occasional elongated fibrocytes. Magnification $\times \mathbf{4 0 0}$.

Fig. 2. Soft tissue of the disc where deposits of basophilic material are interposed among irregular bundles of collagen fibres. Magnification $\times 400$.

Fig. 3. Superficial portion of a disc. Numerous oval or irregularly shaped cells with abundant cytoplasm lie in a loose pericellular matrix. Magnification $\times 400$.

tomography, computerized tomography, threedimensional computerized tomography), revealing the presence in each disc of large internal radioopaque areas. These individuals presented functional defects with serious limitation of motion and articular crepitus and pain, but they did not have any signs of rheumatoid or autoimmune diseases as evidenced by clinical history and clinical, radiological and blood chemistry tests.

After surgical removal the excised discs were rapidly washed in buffered saline solution and fixed in a mixture of glutaraldehyde $(2.5 \%)$ and parafor-
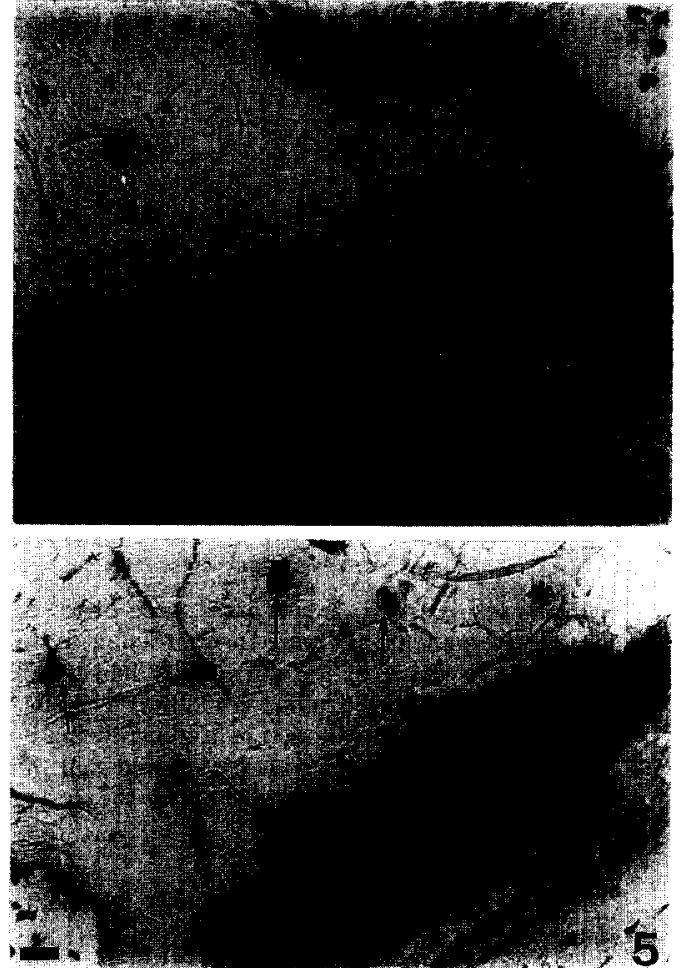

Fig. 4. Calcified disc tissue $(*)$ with some enclosed cells (arrows) is surrounded by unmineralized basophilic layer and external fibrous tissue. Magnification $\times 400$.

Fig. 5. Calcified disc tissue $\left({ }^{*}\right)$ and surrounding fibrous cover. Some cells (arrows) are enclosed within the calcified matrix, others lie in the outer mineralizing border (arrowhead). Elongated fibrocytes are present in the fibrous external tissue. Magnification $\times 400$; bar $=10 \mu \mathrm{m}$.

maldehyde $(2 \%)$ in $0.1 \mathrm{M} \mathrm{Na}$ cacodylate buffer, $\mathrm{pH}$ 7.4 , for $5 \mathrm{hr}$ at $4^{\circ} \mathrm{C}$, rinsed in the same buffer solution and postfixed in $1 \% \mathrm{OsO}_{4}$ in $0.2 \mathrm{M}$ collidine buffer, $\mathrm{pH} 7.4$, for $2 \mathrm{hr}$ at $4^{\circ} \mathrm{C}$. The samples were dehydrated and embedded in epoxy resin and sectioned without mineralization. Semithin sections $(0.5 \mu \mathrm{m})$ were stained with toluidine blue and studied by light microscopy; ultrathin sections $(80 \mathrm{~nm})$ were stained with uranyl acetate and lead citrate and studied by transmission electron microscopy.

Subsequently the sectioning surfaces of the epoxy resin blocks were sputtered with a carbon film and observed in a scanning electron microscope equipped with a Tracor Northern energy-dispersive $X$-ray spectrometer to characterize and identify the chemical composition of the samples. A qualitative analysis of a spectrum in the data memory of the chemical elements from $\mathrm{Na}$ to $\mathrm{U}$ was performed with the IDENT program. The conditions for the microprobe analysis were: accelerating voltage of 15 $\mathrm{kV}$, probe current of $6 \times 10^{-9} \mathrm{~A}$, working distance of $39 \mathrm{~mm}$ and counting time of $30 \mathrm{sec}$.

The same samples were analysed by X-ray powder diffraction to characterize the crystalline phases 

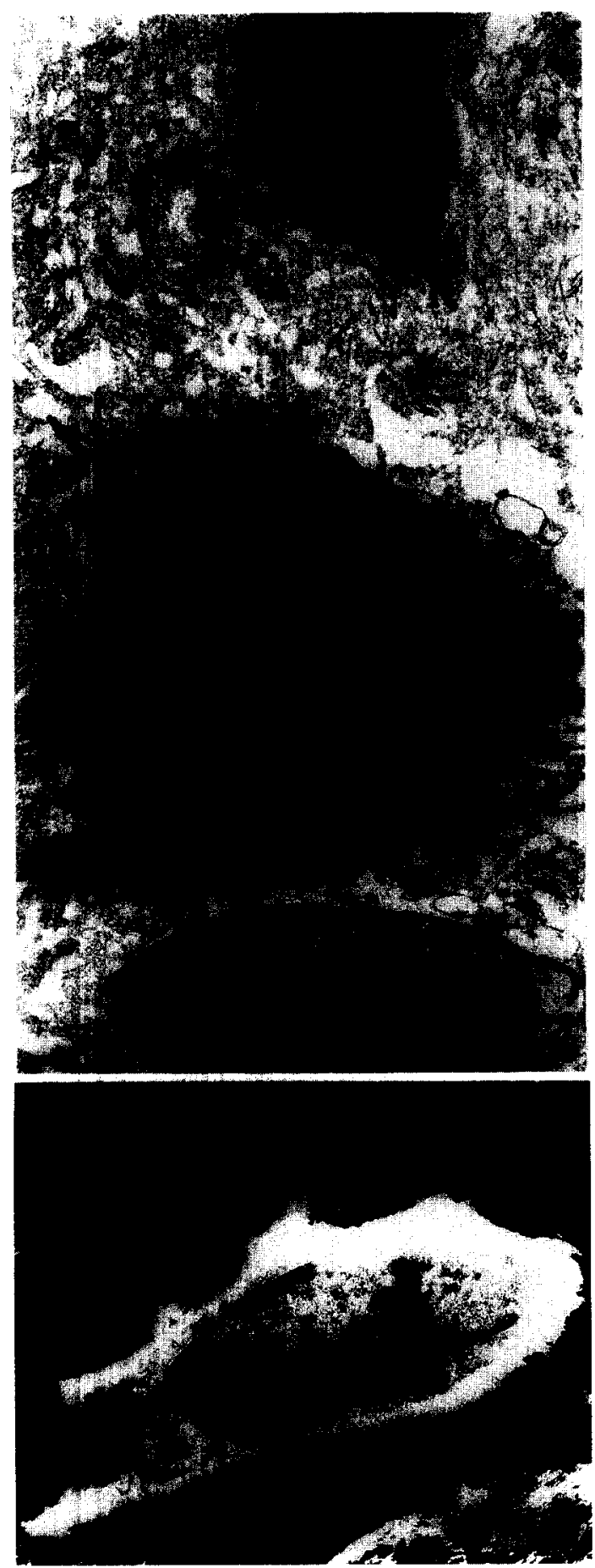

Fig. 6. Electron micrograph of the disc region of Fig. 3. The cells are characterized by abundant cytoplasm with rough endoplasmic reticulum. Golgi apparatus and filaments. The pericellular matrix consists of amorphous material and rare and isolated collagen fibrils. Magnification $\times 6000$.

Fig. 7. Electron micrograph of a degenerated cell completely surrounded by calcified matrix. The collagen fibril banding is not completely masked by the presence of crystallites. Magnification $\times 6500$.
(Bonucci and Graziani, 1975). The hard portion of each sample was separated from the soft tissue, ground in an agate mortar and analysed in the natural state using a Philips PW 1800/10 diffractometer equipped with Digital Microvax 2000 and software APD-1700. Characteristics and variables of the diffractometer were: radiation $\mathrm{Cu} \mathrm{K}, 50 \mathrm{kV}$, $30 \mathrm{~mA}$; graphite monochromator range $2-5020$.

\section{RESULTS}

\section{Light microscopy}

In all the discs an unmineralized soft tissue surrounded and limited the calcified discal area. In two discs the non-calcified tissue consisted of compact bundles of collagen fibres with occasional elongated fibrocytes (Fig. 1). In the other three samples, collagen fibre bundles were disarrayed and sometimes intermingled with deposits of dense basophilic and apparently amorphous material (Fig. 2). One of these discs had a large, superficial zone consisting of a loose tissue containing fewer fibres and large, basophilic and sometimes binuclear cells (Fig. 3).

In the inner part of each disc a large area $(0.3-1$ $\mathrm{mm}^{2}$ ) of hard, calcified tissue was present. It consisted of compact mineralized tissue containing cells enclosed in irregular lacunae (Figs 4 and 5). The calcified areas were variously shaped and had irregular contours. They were surrounded by an unmineralized, dense and highly basophilic layer (10 40 $\mu \mathrm{m})$, consisting of amorphous or granular material containing numerous oval or elongated cells. This layer was continuous with the external fibrous tissue of the discs containing compact bundles of fibres and elongated fibrocytes.

\section{Transmission electron microscopy}

The region of the disc consisting of loose tissue by light microscopy was ultrastructurally characterized by the presence of roundish or oval chondrocyte-like cells (Fig. 6). They exhibited irregular profiles with short and slender processes, abundant cytoplasm rich in rough endoplasmic reticulum, and they were sometimes binucleated. The pericellular matrix consisted of a loose, finely granular and less electron-dense material and scanty collagen fibrils.

The calcified areas of the discs (Fig. 7) consisted of a highly mineralized and compact tissue where packed collagen fibrils were almost completely masked by electron-dense confluent crystallites. Necrotic or severely degenerated osteocyte-like cells with scanty cytoplasm were present in this mineralized tissue. They were contained in lacunae with indented profiles because of a brush border of protruding crystallites. A pericellular space separated the cell surface from the mineralized matrix.

The unmineralized tissue layer outside of the calcified areas consisted of a loose matrix with bundles of variously arranged collagen fibrils (Figs 8 and 9). 

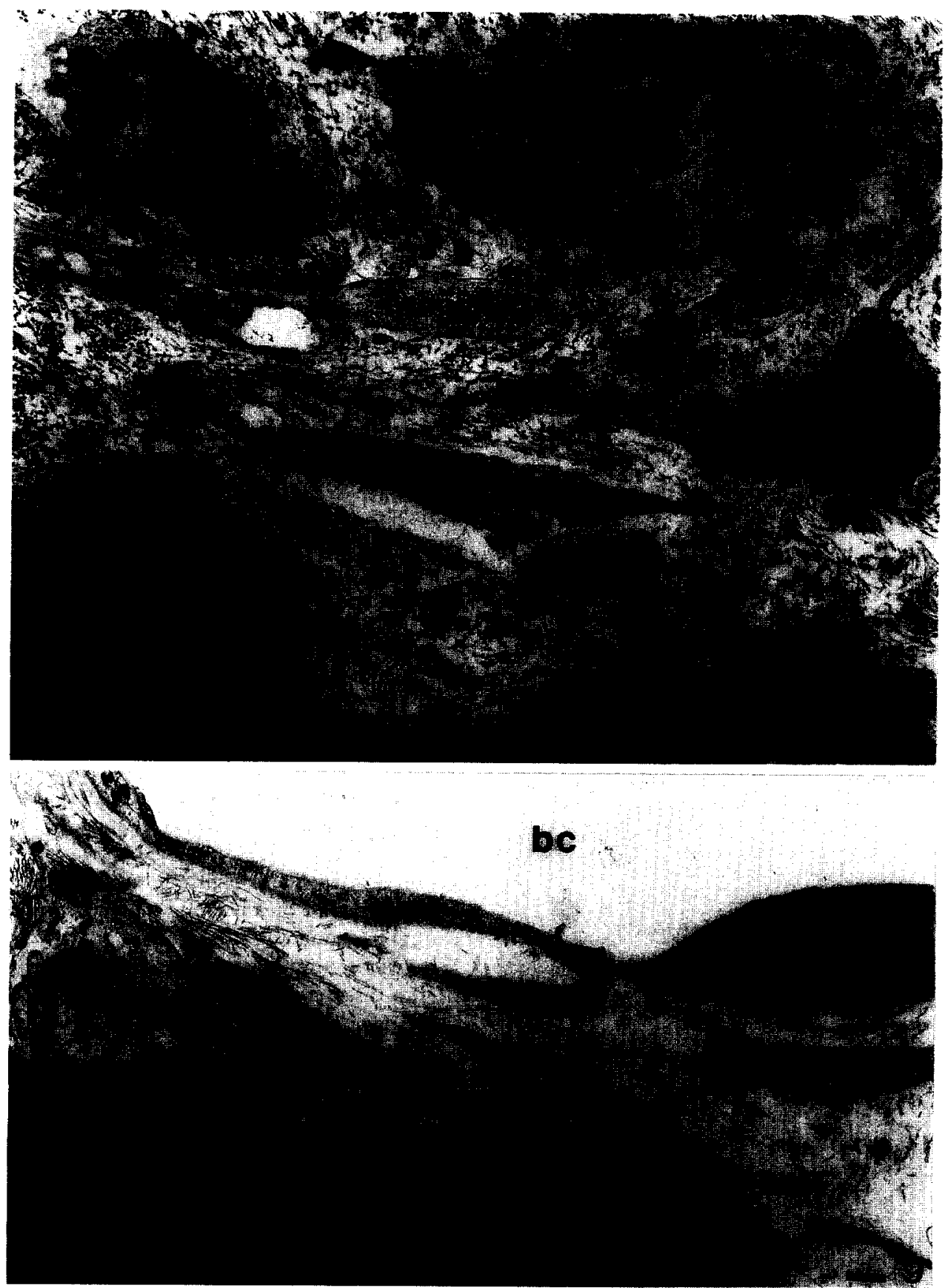

Fig. 8. Electron micrograph of the mineralization front close to the calcified tissue. Numerous elongated cells with irregular protrusions are distributed within an extracellular matrix rich in collagen fibrils. Magnification $\times 6100$.

Fig. 9. Electron micrograph of the border of the mineralizing area. A cell is in contact with the calcified matrix on one side and with collagen fibrils of the mineralizing matrix on the other. At the top a blood capillary (bc) is present. Magnification $\times 6560$; bar $=1 \mu \mathrm{m}$.

These fibrils were thin but fairly dense and they seemed to be continuous with those already covered by the deposition of crystallites. Numerous oval or elongated cells with thin cytoplasmic processes were contained in the matrix of this mineralization front. Blood vessels were present among the cells (Fig. 9).

\section{Energy-dispersive $X$-ray spectrometry}

Analysis of the chemical composition of the calcified portions of the discs showed $\mathbf{C a}$ and $\mathbf{P}$ signals in all samples (Fig. 10). The same investigation (data not shown) performed on the outer fibrous portions of the dises gave no signals. 

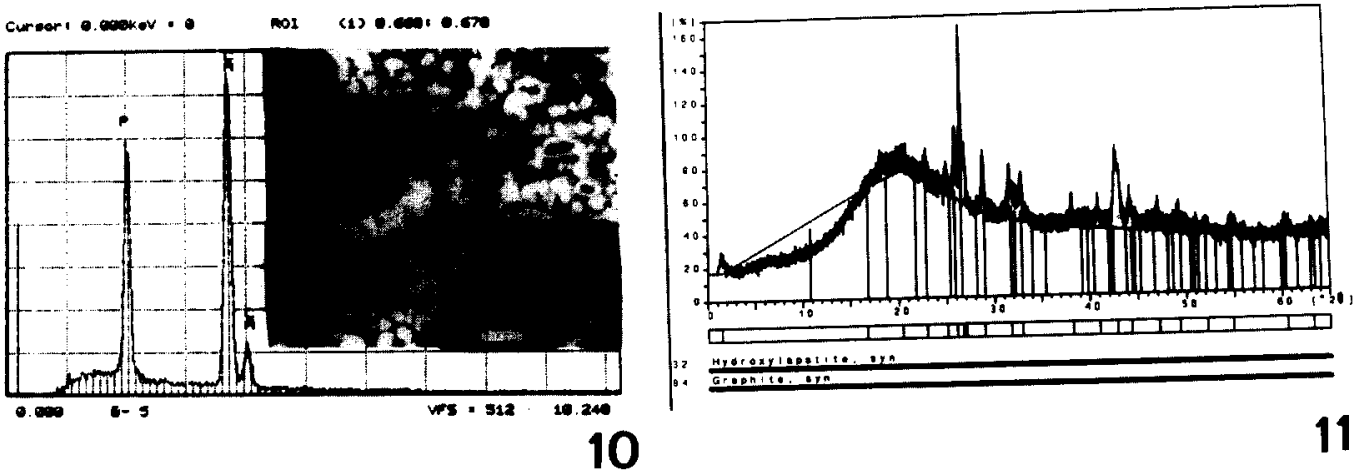

Fig. 10. Energy-dispersive X-ray spectrum (EDS) of the mineralized zone of one disc. In the inset a scanning electron-micrograph of the same area is shown, photographed after EDS analysis. Vertical full scale $($ VFS $)=512$; inset magnification $\times 400$ : $\mathrm{bar}=10 \mu \mathrm{m}$.

Fig. 11. X-ray powder diffraction pattern from the calcified disc of Fig. 10 showing the peaks of hydroxyapatite crystals. The graphite signal is due to the sputtering for scanning electron microscopy

\section{$X$-ray powder diffraction}

The diffraction peaks obtained from each sample identified the crystals of the calcified areas as hydroxyapatite minerals (Fig. 11).

\section{DISCUSSION}

We earlier demonstrated that fibrous tissue of the articular disc may undergo structural modifications following different functional diseases (Piacentini et al. 1994: Marchetti et al., 1995). The main modifications were derangements of the fibrillar component, increased vascularization and cellular proliferation. Moreover, we observed the appearance of radio-opaque, calcified areas in some discs and in endoarticular loose bodies (Piacentini et al., 1995).

Isolated foci of mineral precipitates have been occasionally described in tissues (Shaw and Molineux. 1994). They appear as restricted and occasional features consisting of single aggregates of few crystallites without any structural arrangement. The present morphological (light and transmission electron microscopy) and chemical study demonstrates that large areas of the discs may undergo histological changes producing a woven bone-like tissue. In all samples the mineralized areas were within the dises and were surrounded by a conspicuous envelope of fibrous tissue.

The presence of cells completely enclosed in lacunae of the calcified matrix and the existence of a mineralizing border rich in cells and collagen fibres outside the calcified tissue suggests that this caicification process is not occasional and restricted. On the contrary it appears to result from a complex process that begins in the interior of the discs and subsequently extends because of aggregation of the calcifying nodules. These events result in a woven bone-like mineralized tissue enclosing the cells that had produced the extracellular matrix. These cells could be modified fibroblasts or they may have differentiated from mesenchymal cells that are usually present in the fibrous tissue. The mineralization process with deposition of crystallites in the extracellular matrix may be promoted by vascularization developed in the normally avascular fibrous tissue of the disc. The X-ray diffraction patterns showing the presence of hydroxyapatite crystals in the calcified tissues strengthen the opinion that a specific process of bone-like mineralization occurred in the articular discal tissue.

These kinds of lesions, apart from the structural peculiarities of the mandibular joint, have some clinical and morphological similarities to the production of articular osteophytes. They too are slowly and progressively formed as a result of excessive functional demands and present a structural modification of articular soft lissues (Takenoshita, 1982. 1987)

Our findings demonstrate that disc tissue may undergo profound metaplastic modifications producing bone-like calcified tissuc. These morphological modifications occur after articular dysfunction producing alterations in the biomechanical forces applied to the disc. Vascularization and the possible subsequent modifications in water content and the composition of the extracellular matrix may activate mechanisms leading to the deposition of crystals. their aggregation and then the extension of the mineralized area

Calcification of the fibrous tissue always begins inside the dise, as we have previously described (Piacentini et al., 1994; Marchetti 't al., 1995). Only afterwards do these processes extend to the superficial parts of the disc. In our opinion this sequence of events suggests that the interior of the disc is most susceptible to variations in mechanical stimuli produced among the articular structures. Tho 
morphological patterns described here demonstrate that the modifications in the articular disc result from excessive functional stress in the articular spaces. These lesions can be considered to be the result of progressive and slowly extending pathological processes in which the articular disc loses its capacity to absorb and reduce the functional stress caused by the condier movements on the functional surfaces of the condyle and glenoid.

Acknowledgements - We thank Dr E. Padula and Dr U. Baciliero from the Divisione di Chirurgia MaxilloFacciale-Ospedale San Bortolo, Vicenza, Dr M. Setti from the Dipartimento di Scienze della Terra and Dr M.P. Riccardi from the Centro Grandi Strumenti of the University of Pavia for their valued collaboration. This work was supported by a grant from Ministero dell' Universita(c) e della Ricerca Scientifica e Tecnologica.

\section{REFERENCES}

Berkovitz B. K., Holland G. R. and Moxam B. J. (1992) A Colour Atlas and Text Book of Oral Anatomy, Histology and Embryology. Wolfe Publishing Ltd, London, 217-219.

Bhussry B. R., Suarez F. R. and Sharawy M. (1991) Temporomandibular joint. In Orban's Oral Histology and Embryology (Ed. Bhaskar S. N.), pp. 406-417. Mosby Year Books Inc., St Louis.

Bonucci E. and Graziani G. (1975) Comparative thermogravimetric, X-ray diffraction and electron microscope investigation of burnt bones from recent, ancient and prehistoric age. Lincei Rend. Sc. Fis. Mat. Nat. LIX, $517-532$.

Carvalho R. S., Yen E. H. K. and Suga D. M. (1993) The effect of growth on collagen and glycosaminoglycans in the articular dise of the rat temporomandibular joint. Archs oral Biol. 38, 457-466.

Carlsson G. E., Oberg T., Bergman F. and Fajers C. M. (1967) Morphological changes in the mandibular joint disk in temporomandibular joint pain disfunction syndrome. Acta Odont. Scand. 25, 163-170.

Farrar W. B. (1972) Differentiation of the temporomandibular joint dysfunction to simplify treatment. J. Prosthet. Dent. 28, 629 636 .
Helmy E., Bays R. and Sharawy M. (1988) Osteoarthrosis of the temporomandibular joint following experimental disc perforation in Macaca fascicularis. $J$. Orat Maxillofac. Surg. 46, 979-990.

Helmy E. S., Bays R. A. and Sharawy M. M. (1989) Histopathological study of the human TMJ perforated disk with emphasis on synovial membrane response. J. Oral Maxillofac. Surg. 47, 1048-1052.

Marchetti C., Piacentini C., Farina A.. Bernasconi G. and Calligro A. (1995) A microscopic and immunocytochemical study of structural changes in dysfunctional human temporomandibular joint discs. Archs oral Biol. 40, 549-557.

Mills D. K., Daniel J. C. and Scapino R. (1988) Histological features and in vitro proteoglycan synthesis in the rabbit craniomandibular joint disc. Archs Oral Biol. 33, 195-202.

Oberg Y. T. and Carlsson G. E. (1979) Macroscopic and microscopic anatomy of the temporomandibular joint. In Temporomandibular Joint: Function and dysfunction (Eds. Zarb G. A. and Carlsson G. E.), pp. 101-118. Munksgaard, Copenhagen

Piacentini C., Marchetti C., Bernasconi G., Menghini P. Baciliero U. and Brusotti C. (1994) Collagen fiber arrangement in temporo-mandibular joint (TMJ) disks from human subjects with functional diseases. Scanning electron microscopy investigations. Scanning Microscopy. 8, 207-213.

Piacentini C., Marchetti C., Callegari A., Setti M. Bernasconi G., Baciliero U., Menghini P. and Brusotti C. (1995) Endoarticular loose bodies and calcification: of the disk of the temporomandibular joint Morphological features and chemical composition. Scanning Microscopy 9, 789-796.

Sharawy M., Larke V. and Helmy E. (1987) Ultrastructural alterations in monkey TMJ following disc perforation. J. Dent. Res. 66, 119.

Shaw R. M. and Molineux G. S. (1994) Age-related changes to the surface ultrastructure of the rabbit temporomandibular disc. J. Anat. 185, 577-585.

Stegenga B., de Bont L. G. M. and Boering G. (1989) Osteoarthrosis as the cause of craniomandibular pain and dysfunction. A unifying concept. $J$. Oral Maxillofac. Surg. 47, 249-256.

Takenoshita Y. (1982) Development with age of the human mandibular condyle. Parts I and II. Dentomaxillofac. Radiol. 11, 5-15.

Takenoshita Y. (1987) Development with age of the human mandibular condyle. Histological study. J. Craniomandibular Practice 4, 317 323. 